\title{
The Modified Integrative Weaning Index as a Predictor of Extubation Failure
}

\author{
Viviane MC Boniatti RPT, Márcio M Boniatti MD PhD, Cristiano F Andrade MD PhD, \\ Crislene C Zigiotto RPT, Patricia Kaminski RPT, Samantha P Gomes RPT, \\ Rodrigo Lippert RPT, Diego C Miguel RPT, and Elaine A Felix MD PhD
}

\begin{abstract}
INTRODUCTION: The extubation period is one of the most challenging aspects for intensive care teams. Timely recognition of the return to spontaneous ventilation is essential for reducing costs, morbidity, and mortality. Several weaning predictors were studied in an attempt to evaluate the outcome of removing ventilatory support. The purpose of this study was to analyze the predictive performance of the modified integrative weaning index (IWI) in the extubation process. METHODS: A prospective study was performed in an ICU in a public hospital in Porto Alegre, Brazil, with 59 adult medical-surgical beds. The final population of the study comprised 153 patients receiving mechanical ventilation for over $48 \mathrm{~h}$ who were extubated during the period from February to November 2011. Demographic data and clinical parameters were collected in addition to extubation predictors, including static compliance of the respiratory system, ratio of breathing frequency to tidal volume, tracheal airway-occlusion pressure $0.1 \mathrm{~s}$ after the start of inspiratory flow, and modified IWI. RESULTS: Extubation failure was observed in 23 of the subjects (15\%). Subjects with greater positive fluid balance, lower hemoglobin levels, and lower levels of bicarbonate presented a higher rate of reintubation. The 3 modified IWI values (the first and 30th minute of the spontaneous breathing trial and the difference between them), as well as the other ventilatory parameters and extubation predictors, displayed poor extubation outcome discrimination accuracy. All indexes presented small areas under the receiver operating characteristic curve, and no accurate cutoff point was identified. CONCLUSIONS: We concluded that modified IWI, similar to other extubation predictors, does not accurately predict extubation failure. Key words: mechanical ventilation; weaning; predictive indexes of extubation. [Respir Care 2014;59(7):1042-1047. (C) 2014 Daedalus Enterprises]
\end{abstract}

\section{Introduction}

Although mechanical ventilation is an essential therapy for patients with respiratory failure, it is an invasive procedure and is associated with a number of complications. ${ }^{1,2}$ Approximately $90 \%$ of critically ill patients require me-

\footnotetext{
Ms Boniatti, Dr Boniatti, Ms Zigiotto, Ms Kaminski, Ms Gomes, Mr Lippert, and Mr Miguel are affiliated with the Critical Care Department, Hospital Nossa Senhora da Conceição, Brazil. Dr Andrade is affiliated with the Thoracic Surgery Department, Hospital de Clínicas de Porto Alegre, Brazil. Dr Felix is affiliated with the Anesthesia Department, Hospital de Clínicas de Porto Alegre, Brazil, and the Critical Care Department, Hospital Nossa Senhora da Conceição, Brazil.
}

The authors have disclosed no conflicts of interest. chanical ventilation. ${ }^{3}$ Most of these patients require some form of weaning to remove the invasive ventilatory support, and this process occupies $>40 \%$ of the required mechanical ventilation time..$^{3,4}$

The extubation period continues to be one of the most challenging aspects for intensive care teams. ${ }^{5}$ Timely recognition of the return to spontaneous ventilation is essential for reducing costs, morbidity, and mortality. ${ }^{6}$ Delays in both removing invasive ventilatory support and exces-

Correspondence: Márcio M Boniatti MD PhD, Reis Louzada, 150/302, 90630-130 Porto Alegre, Brazil. E-mail: marciobt@terra.com.br.

DOI: $10.4187 /$ respcare. 02652 
sively early removal are correlated with complications that vary according to the severity of the underlying disease.

Several weaning predictors were studied in an attempt to evaluate the outcome of removing ventilatory support. ${ }^{1,7-13}$ However, none of them have yet presented good results in discriminating the outcome of extubation, even those most used in clinical practices, such as vital capacity, tidal volume $\left(\mathrm{V}_{\mathrm{T}}\right)$, maximal inspiratory pressure, tracheal airway-occlusion pressure $0.1 \mathrm{~s}$ after the start of inspiratory flow $\left(\mathrm{P}_{0.1}\right)$, and ratio of breathing frequency (f) to $\mathrm{V}_{\mathrm{T}}\left(\mathrm{f} / \mathrm{V}_{\mathrm{T}}\right) .4,8,11,14-18$

Recently, a new index was created, the integrative weaning index (IWI). This index evaluates respiratory mechanics, oxygenation, and respiratory pattern in an integrated manner. It demonstrated surprising accuracy for weaning failure, and it was superior to all other predictors. The authors suggest that this index could also be used to predict extubation outcome. ${ }^{14}$

Our objectives in this study were to analyze the predictive performance of the modified IWI in the extubation process and to compare the IWI to other predictors being used. Furthermore, our goal was to evaluate the accuracy of the modified IWI at 2 different points in time: the first and 30th minute of a spontaneous breathing trial (SBT).

\section{Methods}

This prospective study was conducted in the ICU of a public hospital in Porto Alegre, Brazil. The study ICU has 59 medical-surgical beds for adults. Patients requiring mechanical ventilation for over $48 \mathrm{~h}$ and who were extubated during the period from February to November 2011 were included in the study.

The study was approved by the Institutional Ethics Committee. Because the laboratory tests and data collected in this study are part of the routine clinical practice at the hospital, the informed consent requirement was waived.

All patients screened for the study were receiving mechanical ventilation, which was performed using a Servoi, Servos (Siemens-Elema AB, Solna, Sweden) or Evita XL (Dräger, Lübeck, Germany) ventilator. Readiness for weaning from mechanical ventilation was tested when the attending team judged that the patient was ready to begin the weaning process and was based on the following criteria: improvement of the underlying condition that led to acute respiratory failure, afebrile, cardiovascular stability (mean arterial pressure $>65 \mathrm{~mm} \mathrm{Hg}$ with no or minimal dose of vasoactive drugs), adequate mental status with no continuous sedative infusion, $\mathrm{P}_{\mathrm{aO}_{2}}>60 \mathrm{~mm} \mathrm{Hg}$ or $\mathrm{S}_{\mathrm{pO}_{2}}>90 \%$, $\mathrm{F}_{\mathrm{IO}_{2}}<40 \%$, and PEEP $\leq 8 \mathrm{~cm} \mathrm{H} \mathrm{H}_{2} \mathrm{O}$. The SBT was performed through a $\mathrm{T}$-tube as a routine procedure in the unit, and the duration was $30 \mathrm{~min}$.

The compliance of the respiratory system $\left(\mathrm{C}_{\mathrm{RS}}\right)$ was measured using volume control ventilation. When the pres-

\section{QUICK LOOK}

\section{Current knowledge}

Daily spontaneous breathing trials are the standard of care for determining the appropriate timing of ventilator discontinuation. A number of other parameters have been used in an attempt to improve the accuracy of predicting weaning outcomes, but with little success.

\section{What this paper contributes to our knowledge}

The integrative weaning index (IWI) combines respiratory mechanics, oxygenation, and respiratory pattern into a single value to predict weaning success. The IWI did not accurately predict weaning failure.

sure-time curve was without inspiratory efforts from the patient, an inspiratory pause of $1.0 \mathrm{~s}$ was used to conclude the measurement. $C_{R S}$ was calculated by dividing the $V_{T}$ by the difference between the inspiratory plateau pressure and PEEP.

To measure $P_{0.1}$, pressure support was reduced to $7 \mathrm{~cm}$ $\mathrm{H}_{2} \mathrm{O}$, and the $\mathrm{P}_{0.1}$ value was obtained from the average of 3 consecutive measures at 15 -s intervals.

The $f / V_{T}$ was calculated for the first and 30th min of the SBT, while the patient was disconnected from the ventilator, using an analog ventilometer (RM121 Respirometer, Ohmeda Japan, Tokyo, Japan). The $\mathrm{f} / \mathrm{V}_{\mathrm{T}}$ was obtained by dividing the $\mathrm{f}$ by the $\mathrm{V}_{\mathrm{T}} \cdot{ }^{15}$

$\mathrm{P}_{\mathrm{aO}_{2}}$ was obtained through blood gas collection performed before the SBT, and the parameter was used to determine the $\mathrm{P}_{\mathrm{aO}} / \mathrm{F}_{\mathrm{IO}_{2}}$ ratio.

The IWI was created to evaluate respiratory mechanics, oxygenation, and respiratory pattern in an integrated manner. It is calculated as the product of $\mathrm{C}_{\mathrm{RS}}$ and oxygen saturation measured from an arterial blood sample $\left(\mathrm{S}_{\mathrm{aO}_{2}}\right)$ divided by $\mathrm{f} / \mathrm{V}_{\mathrm{T}}\left(\mathrm{IWI}=\mathrm{C}_{\mathrm{RS}} \times \mathrm{S}_{\mathrm{aO}_{2}} /\left[\mathrm{f} / \mathrm{V}_{\mathrm{T}}\right]\right)$. The threshold used to best discriminate the success or failure of weaning was $>25 \mathrm{~mL} / \mathrm{cm} \mathrm{H}_{2} \mathrm{O}$. In our study, we modified some aspects of the IWI, calling it the "modified IWI." We used $\mathrm{S}_{\mathrm{pO}_{2}}$ to replace the $\mathrm{S}_{\mathrm{aO}_{2}}$ measure. This substitution is justified by the good correlation between both ${ }^{19}$ parameters and because it is easier to obtain the former. In addition, measurement was performed at 2 points in time: at the first and 30th min of the SBT. For the latter measurement, we used the same value of $\mathrm{C}_{\mathrm{RS}}$ obtained immediately before the SBT, and the values of $\mathrm{S}_{\mathrm{pO}_{2}}$ and $\mathrm{f} / \mathrm{V}_{\mathrm{T}}$ at its end.

The respiratory variables were measured by previously trained respiratory physiotherapists. The decision to return the patient to mechanical ventilation or proceed to extubation was made by the attending team and was based on signs of intolerance to SBT, such as tachypnea, tachycardia, hemodynamic instability, breathing effort, and change 
Table 1. Demographic Characteristics and Clinical Parameters

\begin{tabular}{|c|c|c|c|}
\hline Variables & $\begin{array}{l}\text { Extubation Success } \\
\quad(n=130)\end{array}$ & $\begin{array}{l}\text { Extubation Failure } \\
\quad(n=23)\end{array}$ & $P$ \\
\hline Age $(y)$ & $56.3 \pm 17.8$ & $62.1 \pm 14.1$ & .14 \\
\hline Male sex & $69(53.1)$ & $12(52.2)$ & $>.99$ \\
\hline SAPS III & $59.8 \pm 15.9$ & $70.6 \pm 19.1$ & .09 \\
\hline COPD & $14(10.8)$ & $3(13.0)$ & .72 \\
\hline Cause of acute respiratory failure & & & .49 \\
\hline COPD exacerbation & $6(4.6)$ & $1(4.3)$ & \\
\hline Pneumonia & $56(43.1)$ & $12(52.2)$ & \\
\hline Cardiac failure & $12(9.2)$ & $3(13.0)$ & \\
\hline Neurological & $10(7.7)$ & $2(8.7)$ & \\
\hline Postoperative & $17(13.1)$ & $2(8.7)$ & \\
\hline Cardiac arrest & $9(6.9)$ & $3(13.0)$ & \\
\hline Miscellaneous & $20(15.4)$ & - & \\
\hline Duration of MV (d) & $7.6 \pm 4.7$ & $8.0 \pm 4.9$ & .68 \\
\hline $\mathrm{Hb}(\mathrm{g} / \mathrm{dL})$ & $9.2 \pm 2.0$ & $8.1 \pm 1.4$ & .013 \\
\hline Lactate $(\mathrm{mmol} / \mathrm{L})$ & $1.3 \pm 0.6$ & $1.4 \pm 0.9$ & .36 \\
\hline Fluid balance during $24 \mathrm{~h}$ before extubation $(\mathrm{mL})$ & $106.4 \pm 1,503.0$ & $803.2 \pm 1,363.4$ & .04 \\
\hline $\mathrm{pH}$ & $7.43 \pm 0.1$ & $7.44 \pm 0.1$ & .78 \\
\hline $\mathrm{P}_{\mathrm{aCO}_{2}}(\mathrm{~mm} \mathrm{Hg})$ & $39.3 \pm 6.9$ & $34.9 \pm 6.0$ & .005 \\
\hline $\mathrm{P}_{\mathrm{aO}_{2}}(\mathrm{~mm} \mathrm{Hg})$ & $111.3 \pm 37.1$ & $107.1 \pm 34.9$ & .62 \\
\hline $\mathrm{HCO}_{3}(\mathrm{mmol} / \mathrm{L})$ & $26.7 \pm 5.0$ & $23.9 \pm 5.1$ & .02 \\
\hline $\mathrm{P}_{\mathrm{aO}_{2}} / \mathrm{F}_{\mathrm{IO}_{2}}$ & $356.4 \pm 118.8$ & $345.5 \pm 122.1$ & .69 \\
\hline ICU mortality & $11(8.5)$ & $10(43.5)$ & $<.001$ \\
\hline Hospital mortality & $38(29.2)$ & $14(60.9)$ & .01 \\
\hline \multicolumn{4}{|l|}{$\begin{array}{l}\text { Data are mean } \pm \mathrm{SD} \text { or } n(\%) \text { unless otherwise stated. } \\
\text { SAPS III }=\text { Simplified Acute Physiology Score III } \\
\text { MV }=\text { mechanical ventilation } \\
\mathrm{Hb}=\text { hemoglobin }\end{array}$} \\
\hline
\end{tabular}

in mental status. Patients were reintubated according to the attending team based on the following criteria: decrease in oxygen saturation to $<88 \%$, despite use of high $\mathrm{F}_{\mathrm{IO}_{2}}$; worsening of arterial $\mathrm{pH}$ or $\mathrm{P}_{\mathrm{aCO}}$; respiratory muscle fatigue; hemodynamic instability; copious secretions that the patient could not remove adequately; and decreased mental status. It is important to highlight that these criteria are those used in the unit, but they were not explicitly checked before reintubation.

Extubation failure was defined as reintubation within $<48$ h. We did not evaluate weaning failure, but, to compare it to other studies, weaning failure was defined by the inability to tolerate SBT.

In addition to the ventilatory parameters and predictive indexes, demographic and clinical data were collected. The Simplified Acute Physiology Score III was calculated upon admission to the ICU. All patients were followed up to determine ICU and hospital mortality.

The data are presented as the mean \pm SD. Continuous numerical variables were analyzed by use of the Student's $t$ test. Receiver operating characteristic curves were constructed to evaluate the discriminatory power of the predictors used. Linear regression analysis was used to eval- uate the relationship between $\mathrm{S}_{\mathrm{aO}_{2}}$ and $\mathrm{S}_{\mathrm{pO}_{2}}$. All the data collected were analyzed using a commercially available statistical program (SPSS version 15.0, SPSS, Chicago, Illinois). $P<.05$ was considered to be statistically significant.

\section{Results}

We screened 358 patients requiring mechanical ventilation for $>48 \mathrm{~h}$ who had been extubated. Two hundred five of these patients were excluded because they had been extubated without performing an SBT $(n=77)$, had experienced accidental extubations $(n=6)$, or were receiving mechanical ventilation with equipment that did not have the devices needed to perform the proposed measurements $(n=122)$. The final population consisted of 153 patients.

The demographic characteristics and clinical parameters of the patients are described in Table 1. The most common cause of initiating mechanical ventilation was pneumonia, which was present in 68 patients $(44.4 \%)$.

Extubation failure was observed in 23 patients (15\%). The success and failure groups did not present any signif- 
Table 2. Ventilatory Parameters at Mechanical Ventilation and Spontaneous Breathing Trial

\begin{tabular}{|c|c|c|c|}
\hline Variables & $\begin{array}{l}\text { Extubation Success } \\
\quad(n=130)\end{array}$ & $\begin{array}{l}\text { Extubation Failure } \\
\quad(n=23)\end{array}$ & $P$ \\
\hline PSV $\left(\mathrm{cm} \mathrm{H}_{2} \mathrm{O}\right)$ & $11.9 \pm 2.0$ & $11.7 \pm 1.6$ & .60 \\
\hline PEEP $\left(\mathrm{cm} \mathrm{H}_{2} \mathrm{O}\right)$ & $5.8 \pm 0.9$ & $5.7 \pm 0.7$ & .53 \\
\hline $\mathrm{F}_{\mathrm{IO}_{2}}$ & $0.32 \pm 0.05$ & $0.33 \pm 0.04$ & .36 \\
\hline $\mathrm{S}_{\mathrm{pO}_{2}}$ & $98.8 \pm 1.5$ & $98.6 \pm 2.1$ & .54 \\
\hline $\mathrm{C}_{\mathrm{RS}}\left(\mathrm{mL} / \mathrm{cm} \mathrm{H}_{2} \mathrm{O}\right)$ & $39.4 \pm 15.5$ & $38.5 \pm 11.0$ & .80 \\
\hline $\mathrm{P}_{0.1}\left(\mathrm{~cm} \mathrm{H}_{2} \mathrm{O}\right)$ & $1.5 \pm 1.1$ & $1.7 \pm 1.3$ & .52 \\
\hline Minute volume (L) & $9.2 \pm 3.3$ & $9.9 \pm 3.1$ & .36 \\
\hline $\mathrm{V}_{\mathrm{T}}(\mathrm{mL})$ & $427.5 \pm 187.0$ & $437.2 \pm 137.3$ & .81 \\
\hline Breathing frequency (breaths/min) & $22.5 \pm 5.9$ & $23.1 \pm 4.7$ & .64 \\
\hline \multicolumn{4}{|l|}{$\mathrm{f} / \mathrm{V}_{\mathrm{T}}$ (breaths $\left./ \mathrm{min} / \mathrm{L}\right)$} \\
\hline First min of SBT & $63.0 \pm 35.9$ & $60.0 \pm 27.2$ & .71 \\
\hline 30th min of SBT & $58.3 \pm 29.9$ & $64.7 \pm 27.7$ & .35 \\
\hline Difference between first and 30th min of SBT & $-4.6 \pm 27.9$ & $4.7 \pm 20.9$ & .13 \\
\hline \multicolumn{4}{|l|}{ Modified IWI (mL/cm $\left.\mathrm{H}_{2} \mathrm{O}\right)$} \\
\hline First min of SBT & $93.9 \pm 105.3$ & $80.1 \pm 56.5$ & .54 \\
\hline 30th min of SBT & $96.3 \pm 98.9$ & $70.7 \pm 49.7$ & .23 \\
\hline Difference between first and 30th min of SBT & $2.5 \pm 58.3$ & $-9.3 \pm 25.3$ & .34 \\
\hline $\begin{array}{l}\text { Data are mean } \pm \mathrm{SD} \text {. } \\
\mathrm{PSV}=\text { pressure support ventilation } \\
\mathrm{C}_{\mathrm{RS}}=\text { compliance of the respiratory system } \\
\mathrm{P}_{0.1}=\text { airway-occlusion pressure } 0.1 \mathrm{~s} \text { after the start of inspiratory } \\
\mathrm{V}_{\mathrm{T}}=\text { tidal volume } \\
\mathrm{f} / \mathrm{V}_{\mathrm{T}}=\text { ratio of breathing frequency to tidal volume } \\
\mathrm{SBT}=\text { spontaneous breathing trial } \\
\mathrm{IWI}=\text { integrative weaning index }\end{array}$ & & & \\
\hline
\end{tabular}

icant differences regarding Simplified Acute Physiology Score III, age, cause for beginning mechanical ventilation, time of mechanical ventilation before extubation, use of noninvasive ventilation after extubation or use of vasoactive drugs. Patients with greater positive fluid balance, lower hemoglobin levels, and lower levels of bicarbonate presented a higher rate of reintubation. Extubation failure was correlated with higher mortality in the ICU and in the hospital (Table 1).

The 3 modified IWI results (first and 30th min of the SBT and the difference between them) were not associated with extubation failure (Table 2). Furthermore, all patients with a modified IWI of $\leq 25 \mathrm{~mL} / \mathrm{cm} \mathrm{H}_{2} \mathrm{O}$ underwent extubation successfully. The other predictors, such as $\mathrm{f} / \mathrm{V}_{\mathrm{T}}$, were also not associated with extubation outcome (Table 2 ). The areas under the receiver operating characteristic curves of the modified IWI are shown in Figure 1.

$\mathrm{S}_{\mathrm{aO}_{2}}$ and $\mathrm{S}_{\mathrm{pO}_{2}}$ showed an excellent correlation $\left(r^{2}=0.91\right.$, $P<.001)$.

\section{Discussion}

We determined that the modified IWI is not accurate for discriminating extubation outcome. To the best of our knowledge, this is the first study to evaluate the IWI for this purpose.

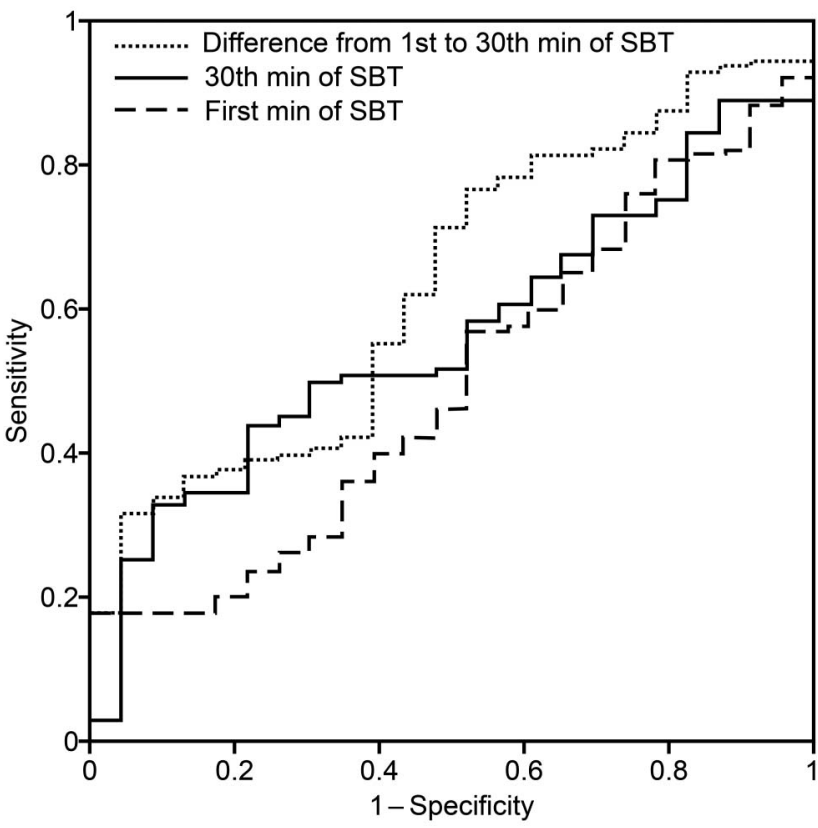

Fig. 1. Receiver operating characteristic curve of modified integrative weaning index. SBT $=$ spontaneous breathing trial.

None of the 3 modified IWI results displayed any association with extubation failure. A recent study ${ }^{14}$ demon- 
strated excellent accuracy of the IWI in evaluating weaning failure. In that study, ${ }^{14}$ the authors also suggested that this index could be used to predict extubation failure. The suggestion was based on an analysis of 10 patients who presented with such an outcome. Some differences between that study and ours might explain the results obtained. First, we must consider the difference between weaning failure and extubation failure. In the study by Nemer et $\mathrm{al}^{14}$ the main outcome analyzed was weaning failure, with a secondary analysis of the patients who presented with extubation failure. In our study, the IWI was tested exclusively to predict extubation outcome. Historically, weaning predictors have shown greater accuracy in discriminating weaning outcome compared with extubation outcome. ${ }^{1,4,6,8,15-18}$ Although the IWI is promising, it possibly presents the same pattern. Second, we did not use a fixed $\mathrm{F}_{\mathrm{IO}_{2}}$. Finally, the increased size of the sample used to evaluate extubation may have contributed to differing results.

It should be highlighted that the use of the modified IWI at the end of the SBT, and the difference between the final and initial modified IWI values also did not present an association with extubation failure. Our hypothesis was that these variables may be more accurate than the initial modified IWI, as already shown for other indexes. ${ }^{20}$

In our opinion, seeking predictive indexes associated with extubation failure is more important than with weaning failure. Tanios et $\mathrm{al}^{21}$ already demonstrated that the use of predictive indexes when deciding to perform an SBT delays extubation. In addition, the test proved to be very secure. ${ }^{22}$ Thus, in clinical practice, the value of a predictive index that suggests that the patient is ready to undergo the SBT is uncertain. However, deciding on the right time to perform extubation is very important. Premature extubation, with a higher risk of reintubation, is associated with a greater need for tracheostomy, a longer stay in the ICU and the hospital, and higher mortality. ${ }^{11,23}$ At the other extreme, late extubation increases the risk of pneumonia, the length of time in the ICU, and hospital mortality. ${ }^{1,2}$ In our study, the patients who required reintubation had ICU mortality rates that were $\sim 5$ times higher than those who were successfully extubated. In this context, a predictive index for extubation outcome would be invaluable. Unfortunately, the modified IWI did not prove very accurate for the latter purpose.

A few clinical parameters appear to be associated with extubation failure. In our study, a greater positive fluid balance, lower hemoglobin levels, and lower levels of bicarbonate increased the chances of reintubation. Some authors ${ }^{24,25}$ had already demonstrated this association with a positive fluid balance and anemia. The relationship between bicarbonate and this outcome is a new finding. These clinical parameters should be tested in future studies and most likely should be evaluated in the weaning process.

The poor accuracy of weaning predictors to evaluate extubation is nothing new. One of the possible explanations is that, besides the clinical parameters cited previously, the quality of coughing and the amount of respiratory secretions are most likely associated with the development of extubation failure. None of these variables are taken into account in the predictive indexes. The bad performance of the modified IWI in predicting extubation outcome in our study most likely has the same explanations. An index that does not include these variables probably will not perform well. Thus, the results were not surprising.

This study has some limitations. The exclusion of patients may have added a bias to the results obtained. In addition, because the number of patients was small, we cannot exclude with certainty that the negative results are not due to a beta error. Furthermore, we used the $30 \mathrm{~min}$ SBT. Perhaps the 2-h SBT could better discriminate extubation outcome and provide different results. ${ }^{26}$ The accuracy of the measurement of the $\mathrm{C}_{\mathrm{RS}}$ when patients are not paralyzed is not clear. We tried to minimize this limitation by avoiding respiratory cycles with inspiratory efforts of the patient after assessing the digital display. The measurement of $\mathrm{P}_{0.1}$ was performed with $7 \mathrm{~cm} \mathrm{H}_{2} \mathrm{O}$ pressure support. As we use the heat and moisture exchange filter this may have influenced this parameter. ${ }^{27-29} \mathrm{Be}$ sides, the $\mathrm{P}_{0.1}$ on the Servo $i$ ventilator was recorded without an occlusion maneuver. Although there are criteria for reintubation in the unit, the decision to reintubate was made by the attending physician. This may have added another bias to the results obtained. Finally, the study was conducted at a single center, making it difficult to generalize the results.

We concluded that the modified IWI as well as other weaning predictors do not accurately predict extubation failure. The indexes derived from the modified IWI (at the 30th minute of SBT and the difference between the first and 30th minute) showed similar results. Thus, we do not yet have a good predictive index for discriminating extubation outcome. Future studies should fill this gap.

\section{REFERENCES}

1. Esteban A, Frutos F, Tobin MJ, Alía I, Solsona JF, Valverdú I, et al. A comparison of four methods of weaning patients from mechanical ventilation. N Engl J Med 1995;332(6):345-350.

2. Tobin MJ. Mechanical ventilation. N Engl J Med 1994;330(15): 1056-1061.

3. Meade M, Guyatt G, Griffith L, Booker L, Randall J, Cook DJ. Introduction to a series of systematic reviews of weaning from mechanical ventilation. Chest 2001;120(Suppl 6):S396-S399.

4. Eskandar N, Apostolakos MJ. Weaning from mechanical ventilation. Crit Care Clin 2007;23(2):263-274. 
5. Soo Hoo GW, Park L. Variations in the measurement of weaning parameters: A survey of respiratory therapists. Chest 2002;121(6): 1947-1955.

6. Kollef MH, Shapiro SD, Silver P, St John RE, Prentice D, Sauer S, et al. A randomized, controlled trial of protocol-directed versus physician-directed weaning from mechanical ventilation. Crit Care Med 1997;25(4):567-574.

7. Boles JM, Bion J, Connors A, Herridge M, Marsh B, Melot C, et al. Weaning from mechanical ventilation. Eur Respir J 2007;29(5):10331056.

8. Epstein SK. Weaning from ventilatory support. Curr Opin Crit Care 2009;15(1):36-43.

9. Conti G. A prospective, blinded evaluation of indexes proposed to predict weaning from mechanical ventilation. Intensive Care Med 2004;30(5):830-836.

10. Capdevila XJ, Perrigault PF, Perey PJ, Roustan JP, d'Athis F. Occlusion pressure and its ratio to maximum inspiratory pressure are useful predictors for successful extubation following T-piece weaning trial. Chest 1995;108(2):482-489.

11. Khamiees M, Raju P, DeGirolamo A, Amoateng-Adjepong Y, Manthous CA. Predictors of extubation outcome in patients who have successfully completed a spontaneous breathing trial. Chest 2001; 120(4):1262-1270.

12. Aboussouan LS, Lattin CD, Anne VV. Determinants of time-toweaning in a specialized respiratory care unit. Chest 2005;128(5): 3117-3126.

13. Wu YK, Kao KC, Hsu KH, Hsieh MJ, Tsai YH. Predictors of successful weaning from prolonged mechanical ventilation in Taiwan. Respir Med 2009;103(8):1189-1195.

14. Nemer SN, Barbas CSV, Caldeira JB, Cárias TC, Santos RG, Almeida $\mathrm{RC}$, et al. A new integrative weaning index of discontinuation from mechanical ventilation. Critical Care 2009;13(5):R152.

15. Yang KL, Tobin MJ. A prospective study of indexes predicting the outcome of trials of weaning from mechanical ventilation. $\mathrm{N}$ Engl J Med 1991;324(21):1445-1450.

16. MacIntyre N, Cook DJ, Ely EW, Epstein SK, Fink JB, Heffner JE, et al. Evidence-based guidelines for weaning and discontinuing ventilatory support: a collective task force facilitated by the American College of Chest Physicians; The American Association for Respiratory Care; and The American College of Critical Care Medicine Chest 2001;120(Suppl 6):375S-395S

17. Epstein SK. Decision to extubate. Intensive Care Med 2002;28(5): 535-546.
18. Savi A, Teixeira C, Silva JM, Borges LG, Pereira PA, Pinto KB, et al. Weaning predictors do not predict extubation failure in simpleto-wean patients. J Crit Care 2012;27(2):221.e1-e8.

19. Pandharipande PP, Shintani AK, Hagerman HE, St Jacques PJ, Rice TW, Sanders NW, et al. Derivation and validation of SpO2/FIO2 ratio to impute for Pao2/FIO2 ratio in the respiratory component of the Sequential Organ Failure Assessment score. Crit Care Med 2009; 37(4):1317-1321.

20. Segal LN, Oei E, Oppenheimer BW, Goldring RM, Bustami RT, Ruggiero S, et al. Evolution of pattern of breathing during a spontaneous breathing trial predicts successful extubation. Intensive Care Med 2010;36(3):487-495.

21. Tanios MA, Nevins ML, Hendra KP, Cardinal P, Allan JE, Naumova EM, et al. A randomized controlled trial of the role of weaning predictors in clinical decision making. Crit Care Med 2006;34(10): 2530-2535.

22. Alía I, Esteban A. Weaning from mechanical ventilation. Crit Care 2000;4(2):72-80.

23. Epstein SK, Ciubotaru RL. Independent effects of etiology of failure and time to reintubation on outcome for patients failing extubation. Am J Respir Crit Care Med 1998;158(2):489-493.

24. Coplin WM, Pierson DJ, Cooley KD, Newell DW, Rubenfeld GD. Implications of extubation delay in brain-injured patients meeting standard weaning criteria. Am J Respir Crit Care Med 2000;161(5): 1530-1536.

25. Frutos-Vivar F, Ferguson ND, Esteban A, Epstein SK, Arabi Y, Apezteguía $\mathrm{C}$, et al. Risk factors for extubation failure in patients following a successful spontaneous breathing trial. Chest 2006;130(6): 1664-1671.

26. Vallverdú I, Calaf N, Subirana M, Net A, Benito S, Mancebo J. Clinical characteristics, respiratory functional parameters, and outcome of a two-hour T-piece trial in patients weaning from mechanical ventilation. Am J Respir Crit Care Med 1998;158(6):1855-1862.

27. Iotti GA, Olivei MC, Braschi A. Mechanical effects of heat-moisture exchangers in ventilated patients. Crit Care 1999;3(5):R77-R82.

28. Campbell RS, David K Jr, Johannigman JA, Branson RD. The effects of passive humidifier dead space on respiratory variables in paralyzed and spontaneously breathing patients. Respir Care 2000; 45(3):306-312.

29. Girault C, Breton L, Richard JC, Tamion F, Vandelet P, Aboab J, et al. Mechanical effects of airway humidification devices in difficult to wean patients. Crit Care Med 2003;31(5):1306-1311.

This article is approved for Continuing Respiratory Care Education credit. For information and to obtain your CRCE

(free to AARC members) visit www.rcjournal.com

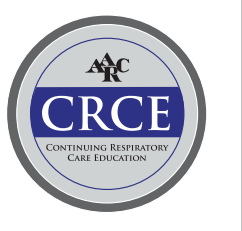

